\section{Massas, normas e violência}

\author{
Masses, norms and violence
}

Michel-Louis Rouquette 1
Abstract This paper stresses the causes of the violent events provoked by masses as, for example, the fights among a group of soccer rooters, trying to contemplate the social and psychological conditions of possibility of those events. A first necessary condition to the manifestation of mass violence is the existence of an orderly distinction, characterized by the formation of a group identity summed up by affiliation signs: emblems, clothes, flags, tattoos, hair style etc. A second condition is the act of minority, once mass violence is always exercised against the minorities. The third condition is the exceptionality, because the time of the violence is an exceptional moment in the daily routine and there is an uncertainty of the everyday norms. The fourth condition refers to a certain culture of violence or to a knowledge of the appropriated manners from its manifestation, diffused by the media. Those four clauses do not explain mass violence completely, but they can help to build up a type of risk scale that could facilitate the prognostic, and even the prevention, in some specific cases.

Key words Violence; Masses
Resumo O artigo aborda as causas dos acontecimentos violentos provocados pelas massas como, por exemplo, as brigas entre torcidas de futebol, procurando refletir sobre as condições psicossociais que envolvem esses acontecimentos. Uma primeira condição, relacionada à manifestação da violência das massas, é a existência de uma distinção ordenada, que se caracteriza pela formação de uma identidade de grupo concretizada por sinais de afiliação: emblemas, roupas, bandeiras, insígnias, tatuagens, corte de cabelo, etc. Uma segunda, é a da minorização, uma vez que a violência das massas se exerce sempre contra as minorias. A terceira condição é a da excepcionalidade, pois o tempo da violência é um momento excepcional no cotidiano. A quarta refere-se a uma certa cultura da violência ou a um conhecimento dos modos apropriados de sua manifestação, difundidos sobretudo pela mídia. Essas quatro condições não explicam por completo a violência das massas, mas podem ajudar a construir uma espécie de escala de risco que poderia facilitar o prognóstico, e até mesmo a prevenção, em casos específicos.

Palavras-chave Violência; Massas

\footnotetext{
1 Departamento

de Psicologia Social. Université de Paris VIII U.F.R.7-2, rue de la Liberté - 93526 Saint-Denis Cedex 02 mi.rouquette@univ.paris 8 fr
} 
Desde sua origem, as ciências sociais têm levado em consideração as massas através da sua violência. No século XIX, Taine, Sighele, Tarde e Le Bon, entre outros autores, foram fascinados pelas multidões revolucionárias e pelas "multidões criminosas", como se elas exprimissem muito mais uma espécie de essência do que um acidente dos agrupamentos. Nisso os estudiosos viram, cada um à sua maneira, uma espécie de fatalidade moderna, ao mesmo tempo ligada a fatores psicológicos permanentes e à generalização da política de massa. Este olhar pode ser com justa razão criticado. Não se trata, todavia, de um simples preconceito desprovido de base empírica já que ele está calcado em uma infinidade de observações, em todos os graus e em todos os países. Periodicamente, por ocasião de tal ou qual febre ideológica ou nacionalista, a atualidade vem nos lembrar a verdade deste ponto de vista e a lembrança aguçada dos totalitarismos do século XX, incompreensíveis sem o esclarecimento da psicologia de massas que terminaria por si só por mostrar a sua pertinência. Doravante, este olhar é limitado pela emergência de novas formas de sociabilidade que escapam às descrições clássicas. Com efeito, não acontece mais, apenas, que a massa já constituída, subjugada ou não por um líder, derrape, desvie, caia no excesso; acontece, sim, de se formar precisamente para desviar, ou seja, de se formar no projeto da delinqüência. Para isto ela se inscreve em quadros morais ou institucionais reconhecidos e geralmente aceitos (o protesto, a auto-defesa, a festa, o esporte); daí então o pretexto aparente ou estipulado da sua reunião passa a não ter mais relação direta com a realidade concreta de sua ação. Eis aqui somente dois exemplos, dos quais cada um de nós poderá reconhecer a freqüência: 1) o fato de um jovem ladrão de carros ter sido abatido pela polícia, fez com que os adolescentes do seu bairro se reunissem e incendiassem vários veículos, pilhassem algumas lojas e enfrentarem acintosamente as forças da ordem; 2) torcedores de um clube de futebol, armados de cassetetes e de garrafas, agridem antes do jogo um grupo de torcedores adversários, provocando ferimentos em vários deles. Ou ainda, decepcionados pelo resultado do seu time, quebram as instalações públicas nas proximidades do estádio.

Pouco importam os detalhes, dir-se-á, mas justamente aqui tudo parece feito de detalhes, o que nos dá a ilusão de se tratar de casos de espécies sempre diferentes. A história cotidiana transcorre assim sob o rosto instável, e aparentemente único da contingência, pois temos muita dificuldade em inserir o que nos acontece, o que observamos, em uma série que poderia ao mesmo tempo dar-lhe uma razão e reduzi-lo a uma simples ocorrência. Os fatos da violência, e ainda mais aqueles que nos são próximos, não escapam a esta regra.

Ora, não caberia aqui a questão de se interrogar seriamente sobre as causas provocadoras de tais acontecimentos (a não ser que se suponha, aliás, que a noção restrita de causalidade tenha aqui um sentido, mas este seria um outro debate). Simplesmente, o presente estado do conhecimento não o permite e, no melhor caso possível, as teorias explicativas disponíveis nada mais são que generalizações de correlações. Talvez não seja prematuro, em compensação, refletir sobre as condições psicossociais de possibilidade destes acontecimentos. Estas condições, quaisquer que sejam, certamente não esgotam todos os aspectos relativos à pertinência do contexto, em sincronia como em diacronia; outras disciplinas, outras abordagens devem ser convocadas para elaborar um quadro forçosamente mais completo da gênese da violência. Embora não seja seguramente suficiente, o papel dos fatores psicossociais é evidentemente necessário pois nem autômatos nem átomos, nem "monades", nem folhas ao sabor do vento, os indivíduos carregam consigo sua identidade, seus envolvimentos e a sua história. Constantes ou ocasionais, seus atos não escapam à influência desta bagagem; e mais, eles se efetivam em função desta mesma bagagem, de seus constrangimentos e de seus recursos. Chegase assim, aqui, a definir um campo onde o encadeamento de condutas pode se produzir e vir a ter um sentido. Isto feito, paramos de tratar de extravagâncias irredutíveis, as quais só prestam para alimentar os catálogos da teratologia social e os impotentes discursos da moral pública. Estamos nos aproximando também, um pouco mais precisamente, dos mecanismos gerais que agem em todos os casos de violência coletiva.

Vamos agora direto ao essencial. Supõe-se que quatro importantes condições, todas relacionadas à noção de norma, estejam agregadas aqui para compor o local e traçar o relevo da cena violenta. O que poderá se produzir, quaisquer que sejam as razões circunstanciais e as formas de detalhe, acontecerá neste qua- 
dro, do qual pode-se dizer, sem abuso de linguagem, que constitui um sistema.

Uma primeira condição necessária à manifestação da violência das massas é a existência do que eu chamaria de cláusula de distinção ordenada uma vez que a massa em questão tenha formado um grupo, ou seja, adotado uma identidade, distingue-se ela mesma pelo menos de um outro grupo conforme uma hierarquia política, econômica, religiosa ou moral (por vezes todas confundidas). Esta cláusula cuja efetivação se traduz por um processo de categorização, permite a percepção do outro e, então, a confrontação com ele; ela é concretizada por sinais visíveis de afiliação: emblemas, roupas, bandeiras, insígnias, tatuagens, corte de cabelo, léxico, e outros. Estes sinais são mais ou menos patentes, mais ou menos uniformes e mais ou menos repetitivos segundo as circunstâncias mas sua função é sempre a de combinar a afiliação (reconhecem-se entre si) e a demarcação (reconhecem também o estrangeiro). A partir daí pode criar raiz uma forma de lógica peremptória cujos atos efetivos serão somente a aplicação. Nesta lógica, toda norma identificatória do grupo-alvo é contra-normativa para o grupo-agente, e aos olhos deste último soa como um desvio: o que "eles" acreditam não deve ser acreditado, o que “eles” fazem não deve ser feito, o que "eles" dizem não merece nada a não ser o silêncio, e assim por diante. Todo grupo é tendencialmente monopolístico; ele torna-se mais ainda quando se distingüe dos outros de modo vantajoso e quando este destaque se traduz por uma ordenação mais definida. Observemos, de passagem, que a este respeito também os grupos morais e moralizadores não constituem exceção.

Esta primeira cláusula, insuficiente por ela mesma devido à sua generalidade, é acompanhada de uma segunda, a da minorização. Com efeito, a violência das massas se exerce sempre contra as minorias: pogroms tradicionais da Europa central contra os judeus, revoltas camponesas (jacqueries) contra os senhores feudais ou representantes do Estado, agressão a imigrantes trabalhadores por operários (Rouquette, 1997), escolha repentina de um bode-expiatório por uma multidão em cólera, ataque a um elemento isolado em uma esquina de rua, afrontamento com policiais percebidos como socialmente minoritários, e assim por diante. A relação da massa violenta com o seu objeto é uma relação de dominação numérica, real ou suposta, nada tem a ver com a violência esporádica exercida por minorias armadas, que é uma escolha estratégica ou tática com vistas a atingir objetivos determinados. Retomando a cláusula precedente, a minorização do adversário ou da vítima corresponde também, no plano ético, a uma minorização de suas normas, a uma localização das mesmas em uma forma de desvio e de exceção que escapa, precisamente, à "normalidade" reivindicada. Este traço só pode reforçar a legitimidade percebida nas ações empreendidas, cujo excesso mesmo se dimensiona, por assim dizer, à profundidade da minorização.

A terceira cláusula é a da excepcionalidade. O tempo da violência é um momento excepcional no desenrolar normal dos dias, pode se tratar de um encontro esportivo, por exemplo, de uma grande festa, de uma manifestação, de uma greve, de um incidente ou de um evento histórico de maior amplitude. Existe aí uma incerteza de normas, uma vez que não se trata mais do tempo habitual que as mesmas têm, justamente na sua função de regular. As normas tratadas agora, são antes de mais nada as de legitimidade de condutas públicas. De uma maneira geral, podem ser declinadas em uma escala graduada em quatro níveis: Non debet/Licet/ Decet/Debet (Não se deve/É permitido/Convém/Deve-se). A situação de parêntese temporário torna possível uma oscilação ou um deslizamento de uma modalidade à outra desta escala: passa-se assim da interdição (Non debet) à permissão excepcional que acredita-se poder se dar (Licet), desta à conveniência (Decet) e desta última ao dever coletivo (Debet). Assim é em linhas gerais a incerteza normativa das massas.

Psicologicamente, pode-se atribui-la a uma baixa de "clarividência normativa", o que vem a ser definido como "um conhecimento" (versus um não-conhecimento) do caráter normativo ou contra-normativo de um tipo de comportamento social, ou de um tipo de julgamento (Py \& Somat, 1991). A hipótese que podemos fazer (e que falta ser validada experimentalmente) é que a clarividência normativa se exerce do melhor modo em uma situação social normal e individualizada. Ora, a massa existe em situação excepcional e sobretudo desindividualizada, como muitos autores clássicos já ressaltaram. A própria desindividualização faz parte, aliás, da exceção nas nossas sociedades que não cessam de valorizar a autonomia do eleitor, a liberdade do con- 
sumidor, a responsabilidade do cidadão, e assim por diante. O sentimento de partilha ou o de comunidade operados pelos agrupamentos, sob o pano de fundo da distinção e da minorização que acabamos de citar, leva a uma suspensão puramente provisória do recurso diferencial ao indivíduo e, portanto, a uma suspensão dos hábitos sócio-cognitivos que lhe são correspondentes.

A quarta cláusula, enfim, igualmente importante e com freqüência não percebida, é propriamente de ordem cultural. As massas não se tornam efetivamente violentas a não ser que possuam uma certa cultura da violência, o que quer dizer um certo conhecimento dos modos apropriados de sua manifestação. Este conhecimento, hoje, vem antes de tudo dos meios de comunicação de massa, mas é falso acreditar, aqui e em qualquer outro lugar, na responsabilidade total e direta dos mesmos. A mídia não incita mais à violência do que à virtude, porque ela mesma é produto de uma configuração sócio-cognitiva mais abrangente que regula tanto a sua produção quanto a sua consumação (ver sobre este ponto Rouquette, 1998). Ela não pode inventar nada senão o que já está inventado, nada suscitar senão o que já seja susceptível de sê-lo. O conhecimento que a mídia difunde sobre a sociedade já é, em suma, um conhecimento comum.

Mas existe ainda mais neste quadro cultural constitutivo dos possíveis. Se considerarmos as formas concretas tomadas pela agressão e pela destruição, pode-se falar de uma verdadeira retórica da violência (Rouquette, 1998). Estas formas, realmente, além dos seus efeitos de comunicação para atores e testemunhas, são repetidas em uma relação de adeqüação com certas circunstâncias. Elas seguem rituais, respondem a regras, e de tal maneira que parecem adaptadas, até legítimas, em um determinado contexto, ainda que fossem inadmissíveis em um outro. Sabe-se bem que a violência dos estádios não é a mesma que a dos subúrbios, que as massas rurais não têm o mesmo estilo de expressão que têm as multidões urbanas, e que os saques às lojas ou o incendiar carros, por exemplo, só se produzem em certos casos. Seria bastante útil inventariar a distribuição destas formas retóricas e ligá-las aos grupos que as colocam em ação em um determinado período. Veríamos então, sem dúvida, como a cognição e a ação coincidem precisamente sobre o plano da sociabilidade. Um tal enfoque permitiria um distanciamento das malfadadas referências à "loucura do momento", à patologia e ao desajuste, sob os quais, a maior parte do tempo, tentamos camuflar a nossa incompreensão sobre a violência das massas.

A distinção, a minorização, a exceção e, enfim, a existência de uma cultura específica, estas quatro cláusulas, repetimos, não explicam por completo uma gama de acontecimentos específicos; elas esboçam o quadro geral necessário ao aparecimento dos acontecimentos de violência de massa. Neste sentido, elas podem ajudar a construir uma espécie de escala de risco que poderia facilitar o prognóstico, e até mesmo a prevenção, em um caso específico. Com efeito, não faltam sinais que avisam, antes de tudo, o aparecimento de semelhante configuração. Cabe à nós reconhecê-los, reagrupá-los e interpretá-los. Nós deveríamos, finalmente, ficar menos surpresos com a irrupção da violência coletiva do que com a nossa inércia, igualmente coletiva, diante do que anuncia esta violência.

\section{Referências}

Py J \& Somat A 1991. Normativité, conformité et clairvoyance: leurs effets sur le jugement évaluatif dans un contexte scolaire, p. 167-193. In J-L Beauvois, RV Joule \& J-M Monteil (eds.), Perspectives Cognitives et Conduites Sociales, 3, DelVal, Cousset.

Rouquette M-L 1997. La Chasse à l'Immigré. Violence, Mémoire et Représentations. Mardaga, Liège.

Rouquette M-L 1998. La Communication Sociale. Dunod, Paris. 